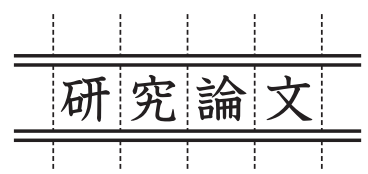

\author{
ゆらぎを付与した水流制御構造の \\ 光造形アディティブ・マニュファクチャリング

\section{Stereolithographic Additive Manufacturing of Fluctuated Patterns for Streamline Modulations in Water Flows}

\author{
野崎 浩 寿*・桐 原聡秀* \\ Hirotoshi NOZAKI and Soshu KIRIHARA
}

(Received September 7, 2018)

\begin{abstract}
Fluctuated structures were designed and fabricated by using stereolithographic additive manufacturing for fluid flows control in living environments. Through the inverse Fourier transformation, fluctuated patterns can be introduced effectively into surfaces of designed solid models automatically. Geometrically modulated artifacts composed of alumina dispersed resin were reproduced by computer aided- design, manufacture. The photo sensitive resin with alumina particles at $55 \mathrm{vol} \%$ were spread on a metal substrate by a knife edge, and an ultra violet laser beam was scanned to create a two-dimensional cross section. Through automatically layer laminations, a three-dimensional object with fluctuated patterns could be fabricated. Water flows on the formed fluctuated components were simulated theoretically and evaluated experimentally.
\end{abstract}

Key Words: Fluctuation, Additive Manufacturing, Stereolithography

\section{1. 緒言}

光造形法プロセスは、任意形状の 2 次元断面を積層して 複雑形状の 3 次元構造を作製する、アディティブ・マニュ ファクチャリング (AM: Additive Manufacturing) 方式の製造 プロセスである。型取りが不要であるため、構造体を高速 成型できるし、切削加工も必要最小限であるため、材料屑 などの排出も抑えられる。次世代のスマートプロセスとし て、国内外で活発な研究開発が進められている11-4)。

これまでの研究において、周期構造 · 自己相似構造 ·傾 斜構造などを光造形し、電磁場・熱場・力場における流れ

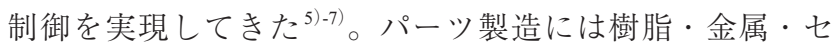
ラミック材料を適宜採用し、最適化された構造により、理 論に基づく機能特性の発現について研究を進めている ${ }^{8)-10)}$ 。 本研究では、自然界に見られるゆらぎパターンを解析し、 光造形を経て人工構造物へ導入することで、周辺を流れる 流体の制御を実践しようと考えた。

蛍の瞬きや木目の模様など、自然界に存在する現象には ゆらぎパターンが存在する。その変動は平均值からの差分 と見なすことができ、時間や空間的な波動として捉えられ、 フーリエ変換によってその特徵を見出すことができる ${ }^{11,12)}$ 。 媒質にゆらぎのパターンを導入することで、物質移動や電 気信号の伝達を安定化させる試みも検証されている。岩や 樹木の表面凹凸を自然波形として表現し、フーリエ変換を
経て、周波数と振幅の関係を描くと、「1/Fゆらぎ」と呼ば れる反比例曲線が得られる13)。

人工的な構造体を設計する際に、ゆらぎ関数を導入する ことで、表面への自然な凹凸付与を試みた。フーリエ逆変 換のパラメータ制御により、ゆらぎ強弱の調整についても 検討した。円筒内壁や球体表面にゆらぎパターンを導入し、 系統的な流体制御シミュレーションを経て、最適化された 構造体として光造形した。

\section{2. 計算ならびに実験方法}

ゆらぎパターンは平均值からの差分であるから、波の一 種とみなせる。波は単純波の和で表すことができ、フーリ 工変換を施すと、周波数と振幅成分の影響力を示すパワー スペクトル密度 (PSD: Power Spectral Density)に相関が見出 せる。自然界に存在するゆらぎは、両者が反比例の関係に あることから「1/Fゆらぎ」と呼ばれている。

はじめに、標準的なゆらぎの特性を表す関数 $P=1 / f^{\gamma}$ に 沿い、仮想的な PSD 曲線を描き Fig. 1 に示した。曲線上の 点を一定差分 $\Delta f$ として周波数 $f_{l} \sim f_{n}$ をとると、対応する PSD 值 $P_{1} \sim P_{n}$ が決まるので、フーリ工逆変換を経て、ゆ らぎを含む自然波形を次の式として得た。

$$
R(\theta)=A_{0}+\Sigma\left\{A_{n} \cos \left(f_{n} \theta\right)+B_{n} \sin \left(f_{n} \theta\right)\right\}
$$

つぎに、区間長 $L$ の自然波形を半径 $r$ で回転させ、Fig.

*大阪大学 接合科学研究所（干 567-0047 大阪府茨木市美穂ヶ丘 11-1）

Joining and Welding Research Institute, Osaka University（11-1, Mihogaoka, Ibaraki, Osaka, 567-0047, Japan） 


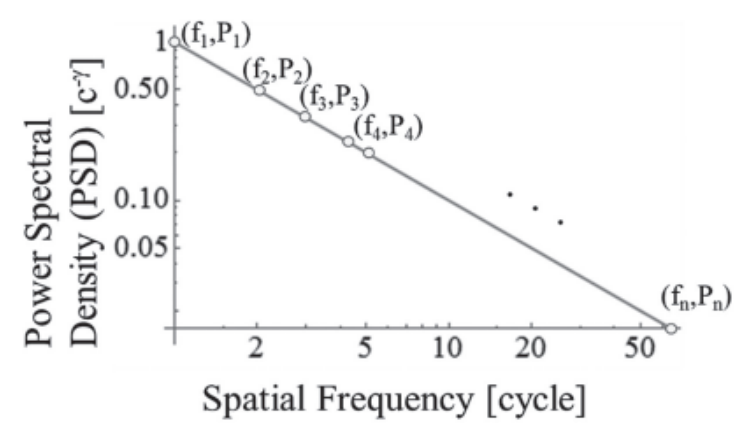

Fig. 1 A power spectral density of a typical $1 /$ f fluctuation in natural patterns.

$\mathrm{L}$

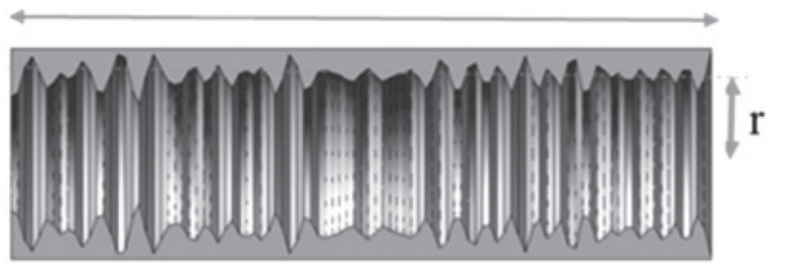

Fig. 2 A computer graphic model of cylindrical tube with fluctuated patterns on the inner wall.

2 に示すような、内壁パターンにゆらぎを有する円筒管を 設計した。ここで、ゆらぎ関数の累乗指数： $\gamma$ 、フーリエ逆 変換の周波数領域: $f_{R 、}$ 管半径 $r$ と管全長 $L$ のアスペクト比 $A_{S}$ を調整し、自然波形のプロファイルを制御した。有限要 素シミュレータ (Cybernet: ANSYS Fluent)を用いて、流体解 析 (CFD: Computational Fluid Dynamics)を実行した。ここで、 管半径 $r=20 \mathrm{~mm}$ 、管全長 $L=100 \mathrm{~mm}$ とし、流速 $10 \mathrm{~m} / \mathrm{s}$ の 水流を想定した。

さらに、光造形法を用いてゆらぎパターンを有する円筒 管と、流体特性を比較するための直導管を作製した。材料 にはアクリル系の光硬化性樹脂 (JSR: KC1287) を用い、平 均粒径 $560 \mathrm{~nm}$ のアルミナ粒子を $55 \mathrm{vol} . \%$ で混合した。自 転公転方式の摚挥脱泡装置を用いて、自転速度 700rpm と 公転速度 300rpm で、処理時間 $5 \mathrm{~min}$ を 3 セット繰り返した。 得られた微粒子ペーストは、シリンジ型の供給器に充填し、 Fig. 3 のごとく光造形装置 (Shashin-Kagaku: SZ-2500)に装 着した。シリンジへ圧搾空気を導入してペーストを吐出し、 ナイフエッジによりステージ上へ層厚 $100 \mu \mathrm{m}$ で平滑塗布 した。ペースト表面に波長 $355 \mathrm{~nm}$ の紫外線レーザを焦点 径 $100 \mu \mathrm{m}$ で照射し、2 次元硬化層を描画形成した。これら の積層工程を繰り返すことで、3 次元構造を作製した。

\section{3. 結果と考察}

直導管に抢ける流体解析の結果を Fig. 4 に示す。管内を 流れる水流が中心部に集まり、流速が増加しているのが確 認できる。このような管内状態では、大きな渦の発生が予 想され、全体の流れを阻害すると考えられる。これに対し

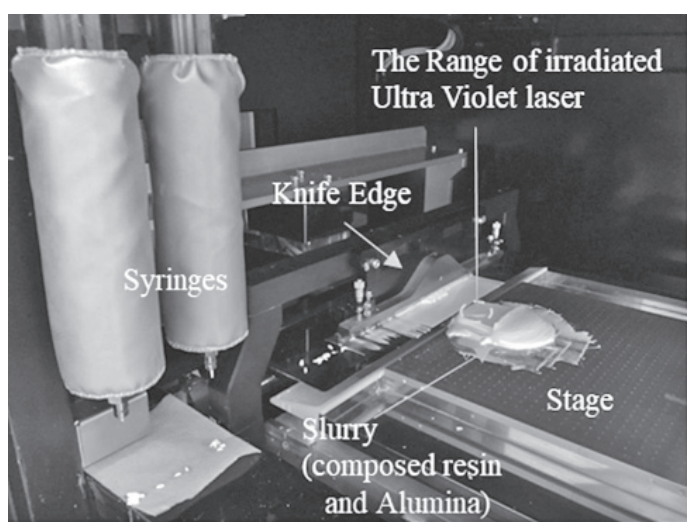

Fig. 3 The mechanical section in stereolithographic additive manufacturing system using nanoparticles dispersing resin paste.

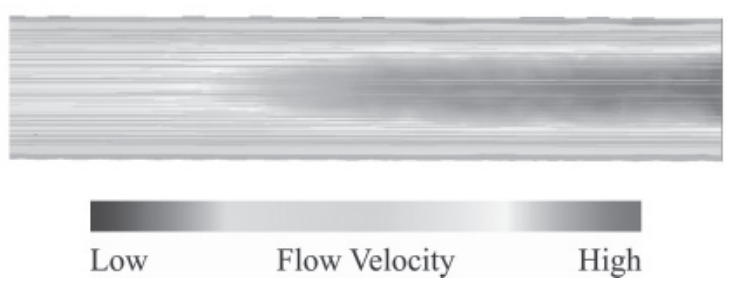

Fig. 4 Visualized stream lines in the straight cylindrical tube through computer fluid dynamics.

て、内壁にゆらぎパターンを付与した場合を Fig. 5 に示す。 ゆらぎ関数の累乗指数： $\gamma$ が小さいと、ゆらぎの振幅が大 きく、内壁付近に比較的大きな渦が多数発生し、全体の流 れが弱められ流速は小さくなる。フーリ工逆変換の周波数 領域: $f_{R}$ が大きいと、内壁の自然波形が細かくなり、極め て小さい渦が多数形成され、管中心に扔いては入水側から 取水側にわたる全域で、ほぼ同じ流速が得られた。管半径 $r$ と管全長 $L$ のアスペクト比 $A_{S}$ が大きいと、ゆらぎ振幅に 対して管が太くなるため、水流に対する凹凸の効果が小さ くなる。以上の結果から、 $\gamma=1 、 f_{R}=2^{4} \sim 2^{5} 、 A_{S}=0.2$ の場 合において、ゆらぎパターンにより管内流速がほぼ一定に なり、安定した流れを示すことが分かった。

ゆらぎパターンは幾何構造であるため、数学的に構造次 元が規定できる。Fig. 6 の示すような Divider-Counting 法を 用いた ${ }^{13)}$ 。直径 $\varepsilon$ のをゆらぎパターンに沿い配列すると き、その個数 $N(\varepsilon)$ との関係から、次式を経て構造次元 $D$ が得られる。

$$
-D=\lim _{\varepsilon \rightarrow+0} \frac{\log N(\varepsilon)}{\log (\varepsilon)}
$$

ここで、Fig. 6 (a) のごとく、ゆらぎパターンの両端長が 1 であると、直径 1 の円が 1 個含まれるので、 $\varepsilon=1 、 N(\varepsilon)$ $=1$ の関係が得られる。また Fig. $6(\mathrm{~b})$ の場合では、直径 $1 / 8$ が 10 個と、 0.2 倍の直径 $1 / 40$ が 1 個含まれるので、 $\varepsilon=$ $1 / 8 、 N(\varepsilon)=10.2$ の関係が得られる。ここで、その他複数の $\varepsilon$ と $N(\varepsilon)$ の関係について、両対数グラフに記入し Fig. 7 に 


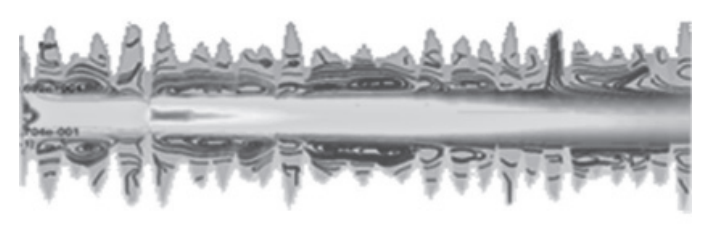

$\gamma=0.5$

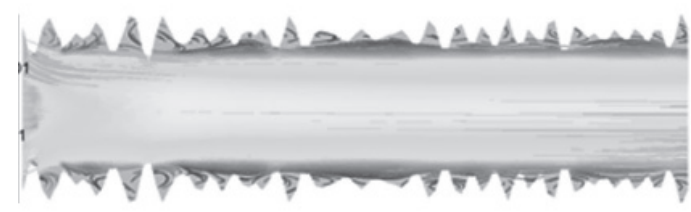

$\gamma=1$

(a) Index Number of Fluctuation Formula
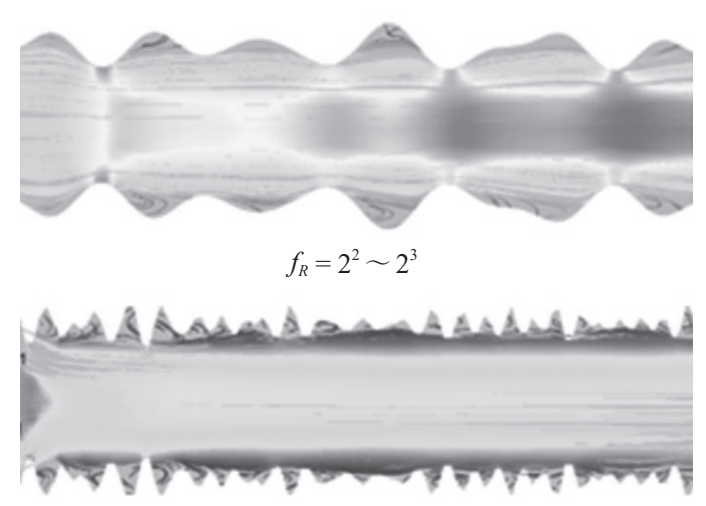

$f_{R}=2^{4} \sim 2^{5}$

(b) Fourier Transformation Range [cycle]

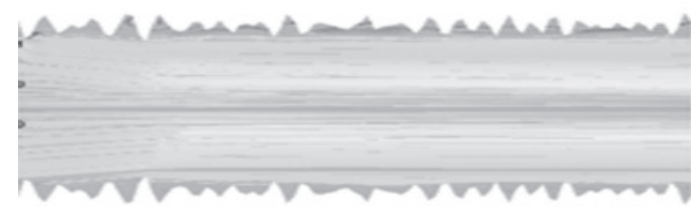

$A_{S}=0.2$

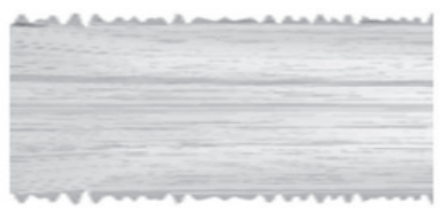

$A_{S}=0.3$

(c) Aspect Ratio of Cylindrical Tube [Radis/Length]

Fig. 5 The visualized stream line in the cylindrical tubes with fluctuated inner wall calculation parameters through inverse Fourier transformation were changed as $(\mathrm{a}),(\mathrm{b})$ and $(\mathrm{c})$.

示した。分布に対して近似曲線を描くとき、その傾きが構 造次元 $D$ を表す。Fig. 6 に示したゆらぎパターンの構造次 元は、Fig. 7 の関係から $D=1.134$ と計算される。次元が非 整数である場合に、幾何学構造は自己相似性を示すことが 知られており、ゆらぎ曲線はフラクタルパターンであるこ とが分かる。規則的な変化を示さない、多様な表面凹凸に より、様々な大きさの渦が、ゆらぎの周辺で多数発生する ため、水流と官内壁の摩擦抵抗が低減され、流れが緩やか

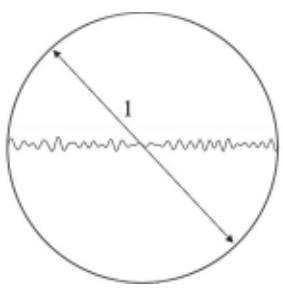

(a) $\varepsilon=1$

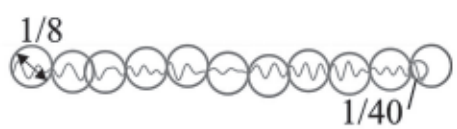

(b) $\varepsilon=1 / 8$
Fig. 6 The Schematically illustrated of calculation methods of the structural dimension in fluctuated patterns by using DividerCounting method.

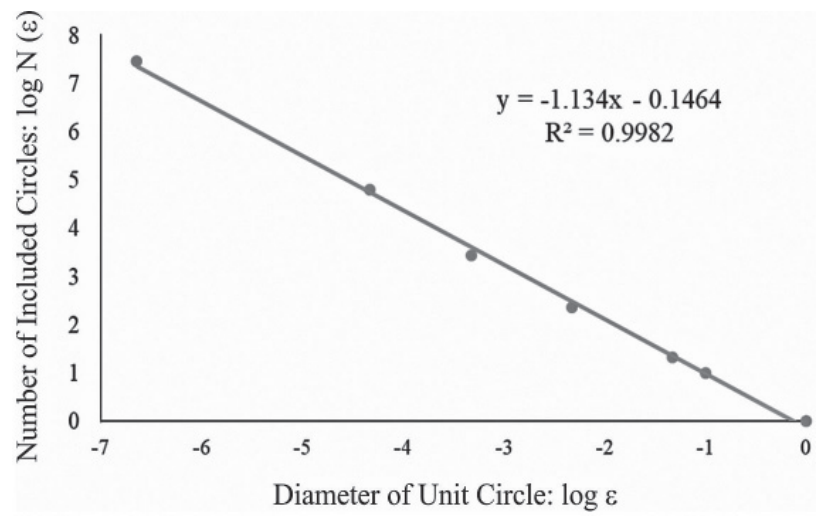

Fig. 7 The numbers of included unit circles in the fluctuated pattern. The relationships between the $\varepsilon$ and $N(\varepsilon)$ were plotted to calculate the structural dimension $D$.

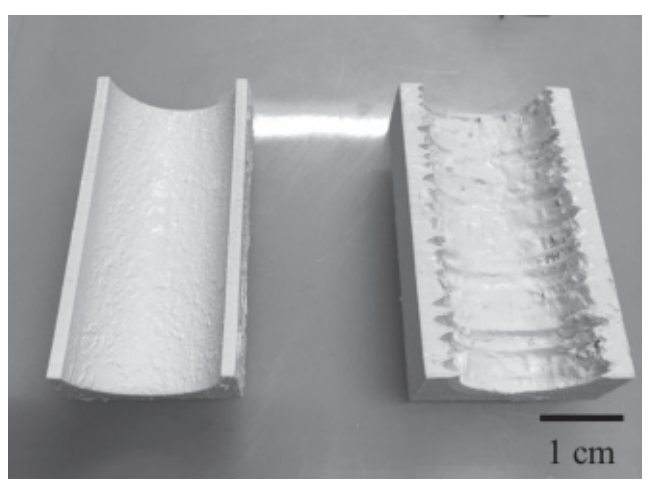

Fig. 8 Cross sections of the cylindrical tubes with or without fluctuated pattern on inner walls fabricated by the stereolithographic additive manufacturing.

になると考えられる。このような効果は、周期的で微細な 凹凸でも実現できると考えられるが、構造に見合う波長の 波が発生すると、定在波の形成や流れの停滞が懸念される。 光造形法により作製した、直導管ならびに内壁ゆらぎ管 をFig. 8 に示す。アルミナ微粒子を分散したアクリル樹脂 製で構成されており、直導管ならびにゆらぎ管へ水道水を 垂直落下させ、勾配 $40^{\circ}$ に固定したときの様子を Fig. 9 (a)、 （b）にそれぞれ示した。直導管に対してゆらぎ管において は、水流の幅が広く、まとわりつくような流れが見られる。 ゆらぎ管の内壁凹凸を最適化した、ゆらぎ関数の累乗指 


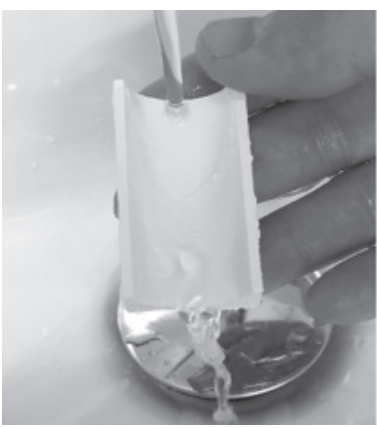

(a)

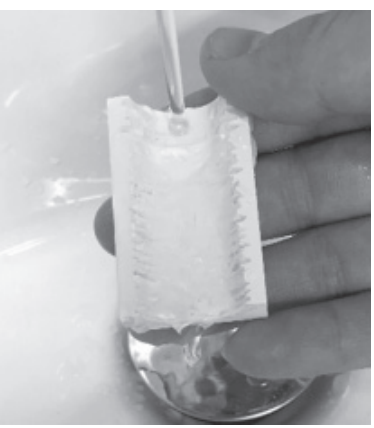

(b)
Fig. 9 Water flows on the half cylindrical tubes with smooth inner wall (a) and fluctuated one.

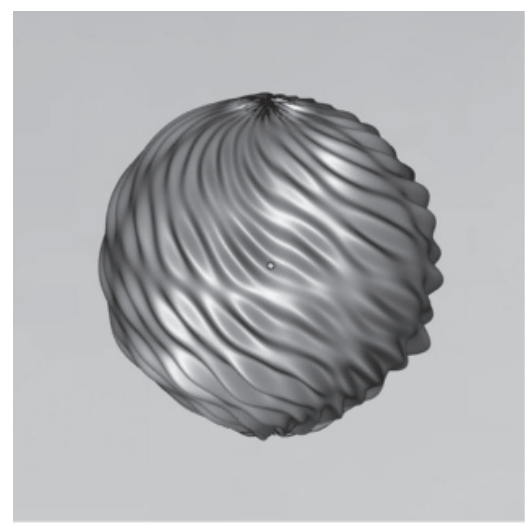

(a)

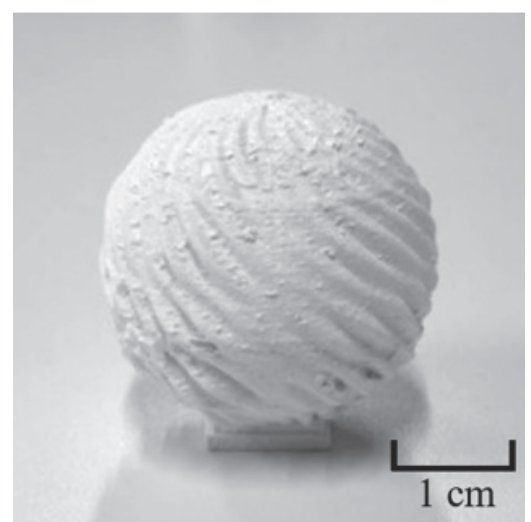

(b)

Fig. 10 Spherical objects with the fluctuated surface patterns designed by the computer graphic (a) and fabricated by the stereolithographic additive manufacturing.

数 $: \gamma$ 、フーリ工逆変換の周波数領域 $: f_{R}$ 、管半径 $r$ と管全 長 $L$ のアスペクト比 $A_{S}$ は、その他の構造体表面に対する 構造改質に利用できる。完全球体の表面にゆらぎパターン を付与した、グラフィックモデルと光造形構造体を Fig. 10 (a)、（b）に示す。造形物表面に細かい粒がみられるが、こ れらは積層工程におけるペースト塗布の際に、流体がゆら ぎ構造に入り込み、不均一な光効果が起こった結果である。

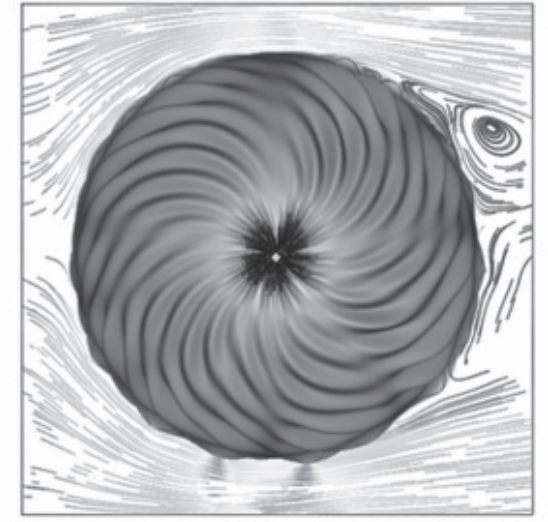

(a)

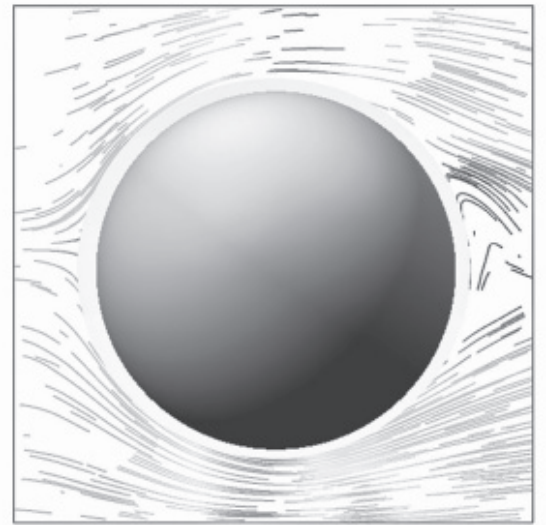

(b)

Low Flow Velocity

High

Fig. 11 The visualized stream lines on an equatorial plane of the spherical model with the optimized fluctuation in the surface wavy pattern.

ゆらぎ構造の造形には、プロセスの最適化が課題として残 された。ゆらぎ表面を有する球体について、赤道面におけ る流水ストリームラインを Fig. 11 (a) に示す。構造体へま とわりつく水流がみられ、Fig. 11 (b) に示す完全球体周辺 のストリームラインと比較しても、ゆらぎパターン付与に よる、流体制御の可能性が示されたと考えられる。

\section{4. 結 論}

自然のゆらぎパターンがフーリエ級数で表されることに 着目し、立体構造物の表面に、制御された凹凸構造を付与 するプロセスについて研究した。逆フーリエ変換における 各種パラメータを制御し、ゆらぎパターンによる水流制御 を検討した。アディティブ・マニュファクチャリングの一 種である光造形法を用いて、アルミナ微粒子を分散したア クリル樹脂を素材に、ゆらぎパターンを構造体を作製した。 円筒管の内壁や球体表面に不規則な凹凸を付与すること で、滑らかな水流を実現できる可能性が示された。 


\section{参考文献}

1）丸谷洋二、光造形法ーレーザーによる三次元プロッター、日 刊工業新聞社、(1990).

2) Y. Marutani, T. Kamitani, J. Photopolymer Science and Technology, 10 (1997) 187.

3) C. Sun, X. Zhang, Sensors and Actuators, 101 (2002) 364.

4) J. Lee, I. Le, D. Cho, Microelectric Eng., 83 (2006) 1253.

5) S. Kirihara, M. Takeda, K. Sakoda, Y. Miyamoto, Solid State Commun., 124 (2002) 135.

6) S. Kirihara, T. Niki, M. Kaneko, Ferroelectrics, 387 (2009) 102.

7) S. Kirihara, M. Takeda, K. Sakoda, K. Honda, Y. Miyamotoa, J. Eur. Ceram. Soc., 26 (2006) 1861.
8) S. Kirihara, Journal of the Ceramic Society of Japan, 123, 1441 (2015) 816.

9) Soshu Kirihara, Welding in the World, 60 (2016) 697.

10) S. Kirihara, K. Nonaka, S. Kisanuki, H. Nozaki, K. Sakaguchi, Materials, 11 (2018) 835.

11）武者利光、ゆらぎの医学、秀潤社、(1985) 175.

12）武者利光、ゆらぎの科学 3、森北出版、(1993) 86 .

13）武者利光、自然界の $1 / \mathrm{F}$ ゆらざ、講談社、(1980).

14）山田俊雄、情報地質、8（1997）177.

代表者メールアドレス

桐原聡秀ｋirihara@jwri.osaka-u.ac.jp 